\title{
Quantitative Characterization of Nut Yield and Fruit Components in Indigenous Coconut Germplasm in Sri Lanka
}

\author{
S. A. C. N. Perera, H. D. M. A. C. Dissanayaka, H. M. N. B. Herath, \\ M. G. M. K. Meegahakumbura, and L. Perera \\ Genetics and Plant Breeding Division, Coconut Research Institute of Sri Lanka, 61150 Lunuwila, Sri Lanka \\ Correspondence should be addressed to S. A. C. N. Perera; chandrikaperera2003@yahoo.com
}

Received 23 May 2014; Revised 24 July 2014; Accepted 24 July 2014; Published 17 August 2014

Academic Editor: Alexandre Sebbenn

Copyright (c) 2014 S. A. C. N. Perera et al. This is an open access article distributed under the Creative Commons Attribution License, which permits unrestricted use, distribution, and reproduction in any medium, provided the original work is properly cited.

Coconut (Cocos nucifera L.) is a tropical palm offering multiple uses. Conservation of coconut germplasm has been undertaken globally in view of its economic importance. This research was designed to evaluate nine Sri Lankan indigenous coconut germplasm representing the three varieties Typica, Nana, and Aurantiaca. Total annual nut yield and the weights of fresh nut, husked nut, split nut, and fresh and dry kernel were scored and analyzed with analysis of variance. The annual average number of bunches varied from 14.9 to 16.8 which is significantly higher than the generally accepted 12-14 bunches in tall coconuts. The high potential of phenotypes Ran thembili and Gon thembili for kernel production was revealed. The high potential of Gon thembili, Sri Lanka Tall, and Ran thembili to produce fibre was also identified. Phenotypes Ran thembili and Gon thembili displayed their potential as pure cultivars and as parents in hybridization. King coconut, Red dwarf, and Bodiri were shown to be suitable as beverage coconuts due to the high production of nuts, bunches, and the quantity of nut water. This study reiterated the importance of conservation and characterization of indigenous coconut varieties globally for their effective use in the genetic improvement of the coconut palm.

\section{Introduction}

Coconut (Cocos nucifera L.) is a perennial palm that is widely distributed in the tropical region of the world. Upon understanding the importance of this crop which provides food and beverage and numerous other raw materials to a multitude of industries, a lot of research effort has gone into the improvement of coconut cultivations in many of the coconut growing countries. Consequently, several concerted programmes have been in place for the collection and exsitu conservation of the global coconut germplasm both in local and in regional or international field gene banks of coconut [1] during the last two decades. Characterization and evaluation of conserved material in a germplasm repository is a prerequisite for the identification of different collections/accessions that possess important features which will become useful in crop breeding. Diverse germplasm for important traits can then be used for the exploitation of hybrid vigour for important traits.
Over 100 accessions comprising of local and exotic material collected both randomly and by using biased sampling techniques have been conserved in the field gene banks of coconut in the Coconut Research Institute of Sri Lanka. Both morphological [2-4] and molecular characterization [5-7] of these conserved coconut germplasm in Sri Lanka have been undertaken over the years. Such studies have shown comparatively low levels of genetic variation among the randomly collected tall coconut populations within the island. However, Perera and Ekanayake [4] reported a considerable amount of morphological variation among many of the indigenous coconut varieties which have been included in the first systematic classification of coconut in Sri Lanka [8].

Liyanage's classification of coconut in Sri Lanka [8] was primarily based on the stature and the breeding behavior of the palms to differentiate the varieties. Accordingly, three main varieties as Tall (Typica), Dwarf (Nana), and Intermediate (Aurantiaca) have been identified and specific phenotypes within varieties have been differentiated by visually 
observable colour, size, and shape variations mainly of the fruit. Therefore, variation in fruit morphology with respect to major traits among the various coconut phenotypes even within a variety is naturally expected as such variation has been a major criterion in the classification within a given variety.

Different components of the fruit provide major economically important produce offered by the coconut palm such as kernel, liquid endosperm, husk, and shell. Therefore the quantitative evaluation of each of these components by weight is a highly important aspect of morphological characterization as it directly deals with the yielding capacity of the coconut palm. Components of the fruit combined with the nut yield of the palm provide the actual yield of the coconut palm in terms of the total kernel, husk, water, or shell produced by a given palm. Then, the objective of the current research was to evaluate a collection of Sri Lankan indigenous coconut varieties and phenotypes conserved in ex-situ field gene banks for nut yield and the weight based analysis of different components of the fruit.

\section{Materials and Methods}

Nine coconut phenotypes belonging to the three coconut varieties (Table 1) conserved in ex-situ field gene banks in Sri Lanka were subjected to fruit component analysis.

Bunch wise nut yield data were recorded in all the coconut phenotypes (except for Kamandala because of the smaller sample size). The number of nuts in the four most mature bunches was counted during one year and from these data the total annual nut yield was obtained.

A total of eighty nuts from each coconut phenotype were sampled as 20 nuts from 10 palms during four times in a year at three monthly intervals. Sampled nuts were subjected to fruit component analysis: weights of fresh nut (FW), husked nut (HNW), split nut (SNW), kernel (KW), and dry weights (scored by oven drying of $100 \mathrm{~g}$ of fresh kernel). The fruit components husk weight (HW), water weight (WW), kernel weight, and shell weight (SW) of each nut were derived from the scored data and the percentages of the same components per nut were also calculated.

The data were analyzed using analysis of variance and general linear models procedure followed by mean separation procedures Duncan's multiple range test and least squares using statistical software package SAS version 8.

\section{Results and Discussion}

3.1. Bunch Production and Nut Yield. The average number of bunches and the average number of nuts recorded by each coconut phenotype within the year were used to calculate the average number of nuts borne in each bunch of coconut (Table 2).

The average number of bunches in the studied coconut phenotypes varied from 14.9 to 16.8 which is significantly higher than the generally accepted 12-14 bunches per year in commercially grown tall coconut phenotypes (Table 2). Bodiri, which is a tall coconut variety and a prolific bearer,
TABLE 1: Coconut phenotypes used in the study.

\begin{tabular}{lc}
\hline Variety & Phenotypes \\
\hline Tall (Typica) & Bodiri, Ran thembili, Gon thembili, \\
& Pora pol, Nawasi, Kamandala, and \\
Dwarf (Nana) & Sri Lanka Tall (SLT) \\
Intermediate (Aurantiaca) & Red dwarf \\
\hline
\end{tabular}

TABLE 2: Bunch production and nut yields of coconut phenotypes.

\begin{tabular}{lccc}
\hline Coconut phenotype & $\begin{array}{c}\text { Number of } \\
\text { bunches }\end{array}$ & $\begin{array}{c}\text { Number of } \\
\text { nuts }\end{array}$ & Nuts/bunch \\
\hline Bodiri & $16.8^{\mathrm{a}}$ & $200^{\mathrm{a}}$ & 11.9 \\
Red dwarf & $15.5^{\mathrm{abcd}}$ & $148^{\mathrm{b}}$ & 9.5 \\
Ran thembili & $16.2^{\mathrm{abc}}$ & $129^{\mathrm{bc}}$ & 8.0 \\
King coconut & $16.5^{\mathrm{ab}}$ & $117^{\mathrm{bc}}$ & 7.1 \\
Gon thembili & $16.1^{\mathrm{abc}}$ & $110^{\mathrm{bcd}}$ & 6.8 \\
Porapol & $14.9^{\mathrm{cd}}$ & $83^{\mathrm{cd}}$ & 5.6 \\
Nawasi & $15.3^{\mathrm{bcd}}$ & $37^{\mathrm{e}}$ & 2.4 \\
SLT & $15.1^{\mathrm{bcd}}$ & $86^{\mathrm{cd}}$ & 5.7 \\
\hline
\end{tabular}

Means with the same letter in each column are not significantly different $(P \leq 0.05)$

recorded the highest value for bunch production. Bodiri is also known to undergo lean periods in bunch emission especially during drier periods of the year. Despite this fact Bodiri was revealed to be the best annual bunch producer. King coconut, being of intermediate type, followed Bodiri for bunch production while the two tall phenotypes Ran thembili and Gon thembili produced over 16 bunches per palm in the year. In contrast, the widely grown commercial coconut phenotype SLT produced only 15 bunches in the year.

With respect to the number of nuts per bunch also Bodiri recorded the highest value. Red dwarf, Ran thembili, KC, and Gon thembili followed Bodiri in that order for the number of nuts produced in a bunch. The same for SLT was shown to be marginal compared even with other talls except for Nawasi which recorded comparatively a very low value for this parameter.

In considering the total number of nuts produced in the year the prolific nut bearer Bodiri became the most superior over the rest of the coconut phenotypes by leading in both parameters. Red dwarf although was not superior in bunch production was revealed to be the second highest nut producer by producing a large number of nuts per bunch being inferior only to Bodiri. Tall coconut phenotype Ran thembili, King coconut, and tall phenotype Gon thembili recorded over 100 nuts per palm in the year. The favoured commercial phenotype SLT once again recorded a marginal value while the tall coconut phenotypes Porapol and Nawasi recorded the least values for all the three parameters measured.

3.2. Components of the Fruit. A vast amount of important information was revealed in this study in the fruit component analysis (Table 3). As has been previously recorded [9] Kamandala revealed the highest values for all the parameters 
TABLE 3: Mean weights of different fruit components in each coconut phenotype.

\begin{tabular}{lcccccccc}
\hline Phenotype & FW & HNW & HW & SNW & WW & SW & KW & DW \\
\hline Bodiri & $977.5^{\mathrm{d}}$ & $455.4^{\mathrm{ef}}$ & $552.0^{\mathrm{d}}$ & $381.1^{\mathrm{de}}$ & $72.8^{\mathrm{d}}$ & $140.2^{\mathrm{de}}$ & $238.1^{\mathrm{d}}$ & $126.4^{\mathrm{de}}$ \\
Red dwarf & $1007.0^{\mathrm{d}}$ & $489.4^{\mathrm{ef}}$ & $517.6^{\mathrm{d}}$ & $358.5^{\mathrm{e}}$ & $131.0^{\mathrm{c}}$ & $122.8^{\mathrm{e}}$ & $110.9^{\mathrm{d}}$ & $110.9^{\mathrm{e}}$ \\
Ran thembili & $1646.0^{\mathrm{bc}}$ & $826.4^{\mathrm{b}}$ & $819.6^{\mathrm{c}}$ & $596.4^{\mathrm{b}}$ & $230.1^{\mathrm{a}}$ & $234.5^{\mathrm{a}}$ & $361.9^{\mathrm{b}}$ & $193.4^{\mathrm{b}}$ \\
King coconut & $1094.3^{\mathrm{d}}$ & $604.4^{\mathrm{d}}$ & $489.9^{\mathrm{d}}$ & $440.9^{\mathrm{d}}$ & $163.5^{\mathrm{b}}$ & $149.9^{\mathrm{d}}$ & $290.9^{\mathrm{c}}$ & $141.3^{\mathrm{d}}$ \\
Gon thembili & $1707.3^{\mathrm{b}}$ & $735.0^{\mathrm{c}}$ & $972.3^{\mathrm{b}}$ & $440.9^{\mathrm{c}}$ & $184.2^{\mathrm{b}}$ & $205.7^{\mathrm{b}}$ & $343.3^{\mathrm{b}}$ & $177.7^{\mathrm{c}}$ \\
Porapol & $1034.7^{\mathrm{d}}$ & $446.1^{\mathrm{ef}}$ & $588.6^{\mathrm{d}}$ & $404.1^{\mathrm{d}}$ & $41.5^{\mathrm{e}}$ & $208.3^{\mathrm{b}}$ & $195.2^{\mathrm{e}}$ & $114.8^{\mathrm{e}}$ \\
Nawasi & $1490.9^{\mathrm{c}}$ & $531.0^{\mathrm{e}}$ & $959.9^{\mathrm{b}}$ & $437.3^{\mathrm{d}}$ & $93.7^{\mathrm{d}}$ & $183.7^{\mathrm{c}}$ & $254.0^{\mathrm{d}}$ & $138.0^{\mathrm{d}}$ \\
Kamandala & $2079.4^{\mathrm{a}}$ & $952.8^{\mathrm{a}}$ & $1128.7^{\mathrm{a}}$ & $695.2^{\mathrm{a}}$ & $259.5^{\mathrm{a}}$ & $244.0^{\mathrm{a}}$ & $451.2^{\mathrm{a}}$ & $224.8^{\mathrm{a}}$ \\
SLT & $1565.0^{\mathrm{c}}$ & $696.2^{\mathrm{c}}$ & $868.8^{\mathrm{bc}}$ & $526.2^{\mathrm{c}}$ & $170.0^{\mathrm{b}}$ & $225.2^{\mathrm{ab}}$ & $301.0^{\mathrm{c}}$ & $163.1^{\mathrm{c}}$ \\
\hline
\end{tabular}

Weights of fresh nut (FW), husked nut (HNW), split nut (SNW), kernel (KW) and dry weights (scored by oven-drying of $100 \mathrm{~g}$ of fresh kernel), and the fruit components; husk weight (HW), water weight (WW), kernel weight, and shell weight (SW).

Means with the same letter in each column are not significantly different $(P \leq 0.05)$.

scored. In general Kamandala was followed by Ran thembili and Gon thembili and these three tall coconut phenotypes outperformed all the other coconut phenotypes studied in this experiment with respect to fruit components. Intermediate coconut phenotype King coconut recorded medium values while the dwarf phenotype Red dwarf recorded the lowest values for the measured characters.

Kernel is currently the main economically important fruit component, followed by the husk. The highest per nut kernel producer, Kamandala, was followed by Ran thembili and Gon thembili with statistically equal performances. The main commercial cultivar SLT was inferior to both Ran thembili and Gon thembili in kernel production. With respect to husk, which is another important component, Kamandala was followed by Gon thembili and Ran thembili, respectively, and for the shell Kamandala was followed by Ran thembili and Gon thembili in that order with statistically significant differences as shown in Table 3. Both King coconut and Red dwarf are predominantly used as beverage coconuts and out of the two coconut phenotypes King coconut contained a higher amount of liquid endosperm.

Although nut yield recording was not undertaken in the coconut phenotype Kamandala in the current study, this phenotype is reported to produce a low number of nuts [9]. Accordingly Kamandala cannot be recommended as an economical cultivar for wide-scale cultivation. However, the current study provide ample evidence for the superiority of both Ran thembili and Gon thembili with respect to nut yield and kernel, husk, and shell components over the predominantly grown commercial cultivar, SLT. Considering both nut number and the amount of liquid endosperm king coconut is the best as beverage coconuts as has been accepted in Sri Lanka.

3.3. Kernel Production. The tall coconut variety Gon thembili fared well above SLT which is commercially the most accepted nut and kernel producer in Sri Lanka. Bodiri, Red dwarf, and King coconut also recorded kernel weights greater than that of SLT mainly due to the higher nut production rather than the per nut kernel content. The two tall coconut phenotypes Porapol and Nawasi recorded the lowest values

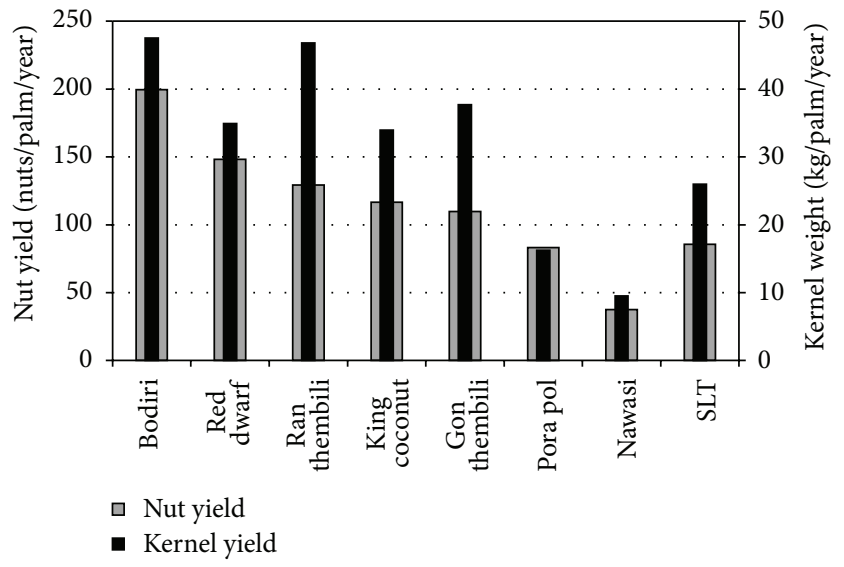

FIGURE 1: Nut and kernel yields in different coconut phenotypes.

for both the nut number and per palm kernel content (Figure 1).

3.4. Comparison of the Percentages of Each Component. Kernel and husk are currently the most economically important components of the coconut. Out of all the components of the fruit, husk was the heaviest component surpassing $50 \%$ by weight in all the studied phenotypes except King coconut (Figure 2). The highest percent husk weight of 65 was recorded in Nawasi. Nawasi has been characterized by its soft mesocarp (husk). This study provides evidence for the mesocarp of Nawasi to be the heaviest component of the nut by a higher margin, compared with the other varieties of coconut included in the study. Coconut phenotypes Porapol, Gon thembili, SLT, Bodiri, and Kamandala recorded husk percentages varying from 57 to 54 which can be considered as the general range for the husk percentage of a coconut. The popular beverage variety King coconut recorded the lowest husk percentage (45\%) among the studied phenotypes. Red dwarf, which is used as beverage coconuts, also recorded a generally low percentage of 51, while the tall phenotype Ran thembili recorded a husk percentage of 50 . 


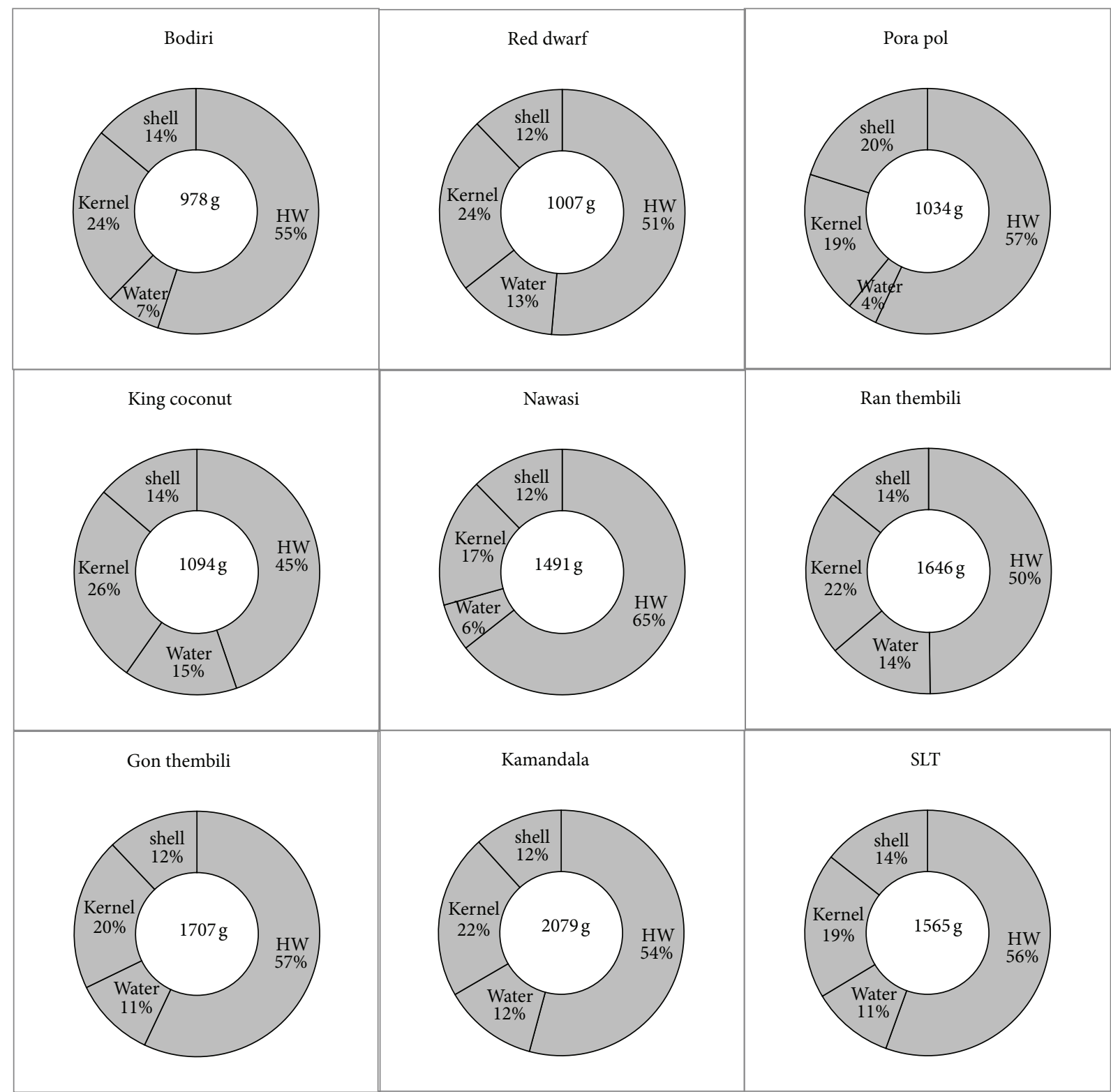

FIgURE 2: Percentage of each fruit component in different coconut phenotypes. Total fruit weights are given in the middle of the circle.

Fruit component kernel weight was the second heaviest in studied coconut phenotypes except for Pora pol which had a greater percentage of shell than kernel. Kernel content varied from $17 \%$ in Nawasi which was the lowest to $26 \%$ in King coconut. The reason for the reduction in percent kernel in Nawasi is the heavier kernel compared with other phenotypes. King coconut, Red dwarf, and Bodiri recorded the highest percent kernel weights recording over $24 \%$. However, none of these three phenotypes are popular for kernel products. SLT, despite being the predominant commercial variety which is widely planted for kernel yield, scored only $19 \%$ for kernel percentage. The same for Gon thembili and Ranthembili were 20 and $22 \%$, respectively, indicating the high potential of the two latter Typica phenotypes for kernel production.
With respect to shell and water (liquid endosperm) weights Red dwarf, King coconut, Ran thembili, Gon thembili, and Kamandala reported more or less equal percentages varying from $12-14 \%$ and $11-15 \%$ for shell and water, respectively. Bodiri was a deviation recording twice the weight for shell (14\%) than water (7\%). As discussed previously many of the other components were much lower in Pora pol allowing for a higher percentage of shell and as a result this phenotype recorded the lowest percent water content of $4 \%$. The tall coconut phenotype Nawasi also recorded a lower percentage for water weight mainly because of the higher content of husk in the nuts of Nawasi. The main commercial cultivar SLT recorded a higher weight for shell (14\%) than water (11\%).

Liyanage [8] based on husk nut and copra weights identified SLT and Kamandala to possess the potential to 
incorporate higher per nut kernel content in coconut breeding. In a more recent study [4] leaf, inflorescence, and fruit diversity of Sri Lankan indigenous coconut varieties was studied using multivariate discriminating methods. This study also reported a high diversity for fruit characters and the need for a more extensive quantitative analysis was emphasized.

The most important revelation of the current study is the high potential of the tall coconut phenotypes Ran thembili and Gon thembili for kernel production. Both these phenotypes fared well above the widely grown commercial coconut cultivar SLT. This potential of Gon thembili as a nut and kernel producer over SLT has previously been reported [10] indicating the high potential of Gon thembili as a pure cultivar. The current study further showed Gon thembili, SLT, and Ran thembili to possess higher weights of husk, which is the raw material for several important fibre and coir dust based industries. Kernel and husk along with shell are the three most important components of the mature coconut and any commercially grown cultivar should ideally possess satisfactory production capacities of these components. The current study provides ample evidence for Ran thembili and Gon thembili to possess these characteristics indicating the suitability of these two phenotypes as pure cultivars as well as candidates in a hybridization programme to transmit the characters. With the information revealed in the current study both Red dwarf and Bodiri can be recommended to be promoted as beverage coconuts in addition to King coconut due to their high nut and bunch production rates as well as the quantity of nut water.

Finally the current study reiterates the importance of conservation, characterization, and multiplication of indigenous coconut varieties and phenotypes in the world for them to be effectively used in the genetic improvement of the coconut palm.

\section{Conflict of Interests}

The authors declare that there is no conflict of interests regarding the publication of this paper.

\section{Acknowledgment}

Financial assistance from the Global Crop Diversity Trust for the characterization of indigenous coconut varieties in Sri Lanka is gratefully acknowledged.

\section{References}

[1] J. G. Ohler, Modern Coconut Management, FAO, Rome, Italy, 1999.

[2] S. A. C. N. Perera and W. M. U. Fernando, "Multivariate discrimination of coconut germplasm using inflorescence morphological characters," in Proceedings of the Sri Lanka Association for the Advancement of Science, vol. 56, p. 97, 2000.

[3] S. A. C. N. Perera, K. G. Ekanayake, and R. B. Attanayake, "Characterization of conserved coconut germplasm in Sri Lanka with morphological descriptors," CORD, vol. 25, no. 1 , pp. 46-53, 2009.
[4] S. A. C. N. Perera and G. K. Ekanayake, "Characterization of Sri Lankan indigenous coconut (Cocos nucifera L.) varieties for diversity in quantitative morphology," Tropical Agriculturist, vol. 157, pp. 25-42, 2008.

[5] L. Perera, J. R. Russell, J. Provan, and W. Powell, "Levels and distribution of genetic diversity of coconut (Cocos nucifera L., var. Typica form typica) from Sri Lanka assessed by microsatellite markers," Euphytica, vol. 122, no. 2, pp. 381-389, 2001.

[6] L. Perera, J. R. Russell, J. Provan, J. W. McNicol, and W. Powell, "Evaluating genetic relationships between indigenous coconut (Cocos nucifera L.) accessions from Sri Lanka by means of aflp profiling," Theoretical and Applied Genetics, vol. 96, no. 3-4, pp. 545-550, 1998.

[7] N. P. Dasanayaka, M. D. T. J. Everard, H. E. Karunanayake, and H. G. Nandadasa, "Characterization of coconut germplasm by microsatellite markers," Tropical Agricultural Research, vol. 15, pp. 51-61, 2003.

[8] D. V. Liyanage, "Varieties and phenotypes of coconut palms grown in Ceylon," Ceylon Coconut Quarterly, vol. 9, pp. 1-10, 1958.

[9] V. D. Liyanage, R. T. M. Wickramaratne, and C. Jayasekara, "Coconut breeding in Sri Lanka: a review," Cocos, vol. 6, no. 1, pp. 1-26, 1988.

[10] S. A. C. N. Perera, "Gon thembili: its undermined potential," Coconut Technology Update of the Coconut Research Institute of Sri Lanka, vol. 2, pp. 3-4, 2010. 

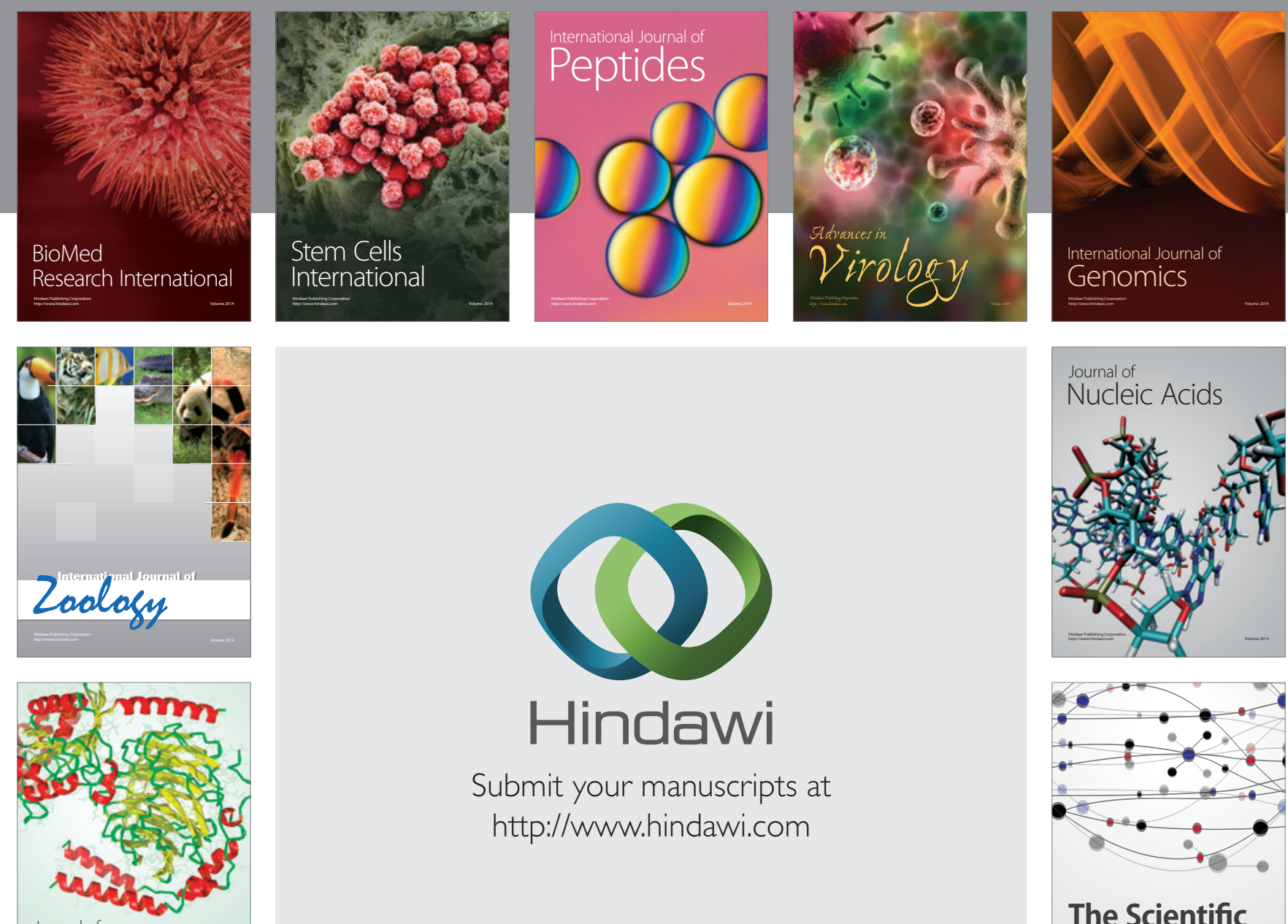

Submit your manuscripts at

http://www.hindawi.com

Journal of
Signal Transduction
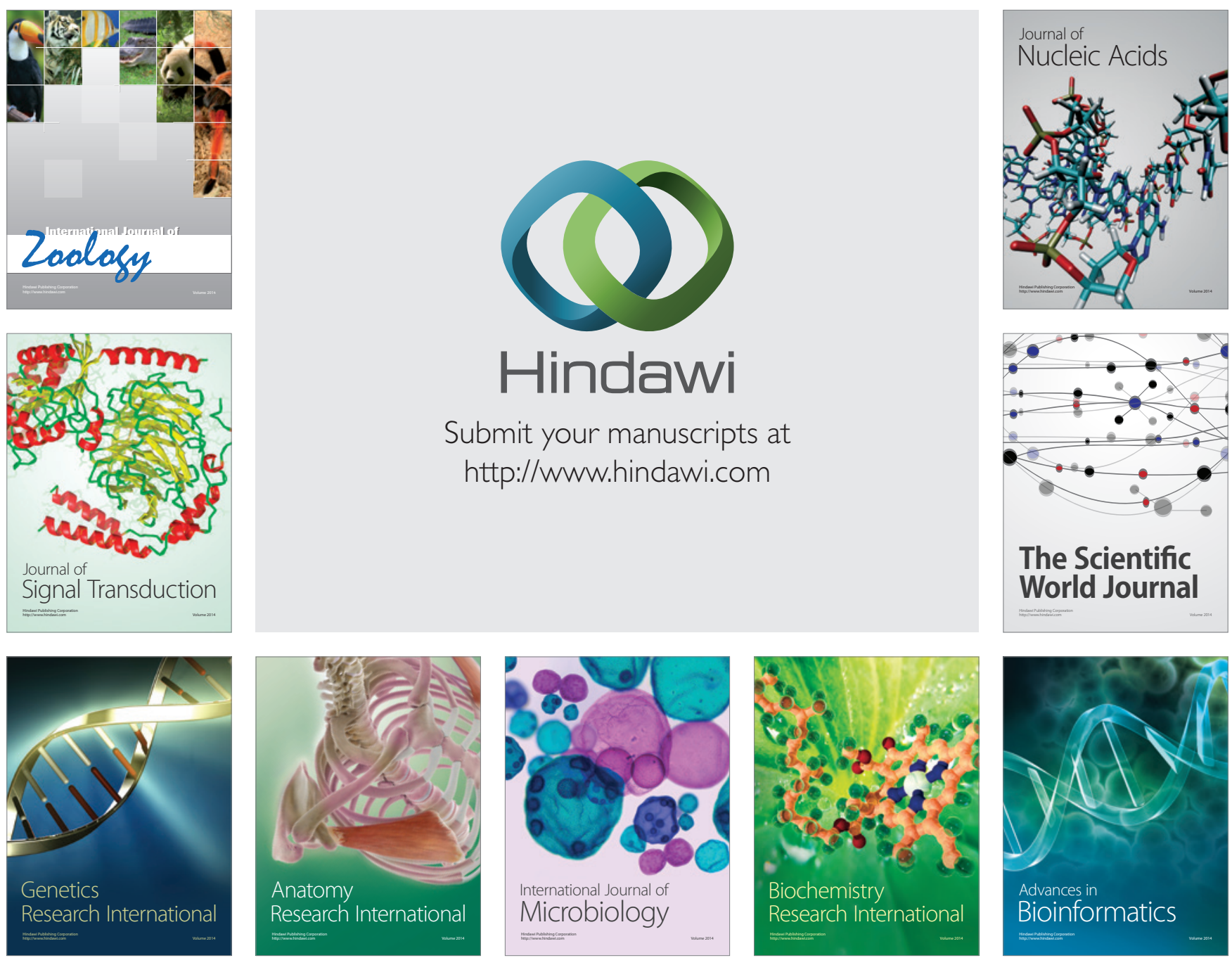

The Scientific World Journal
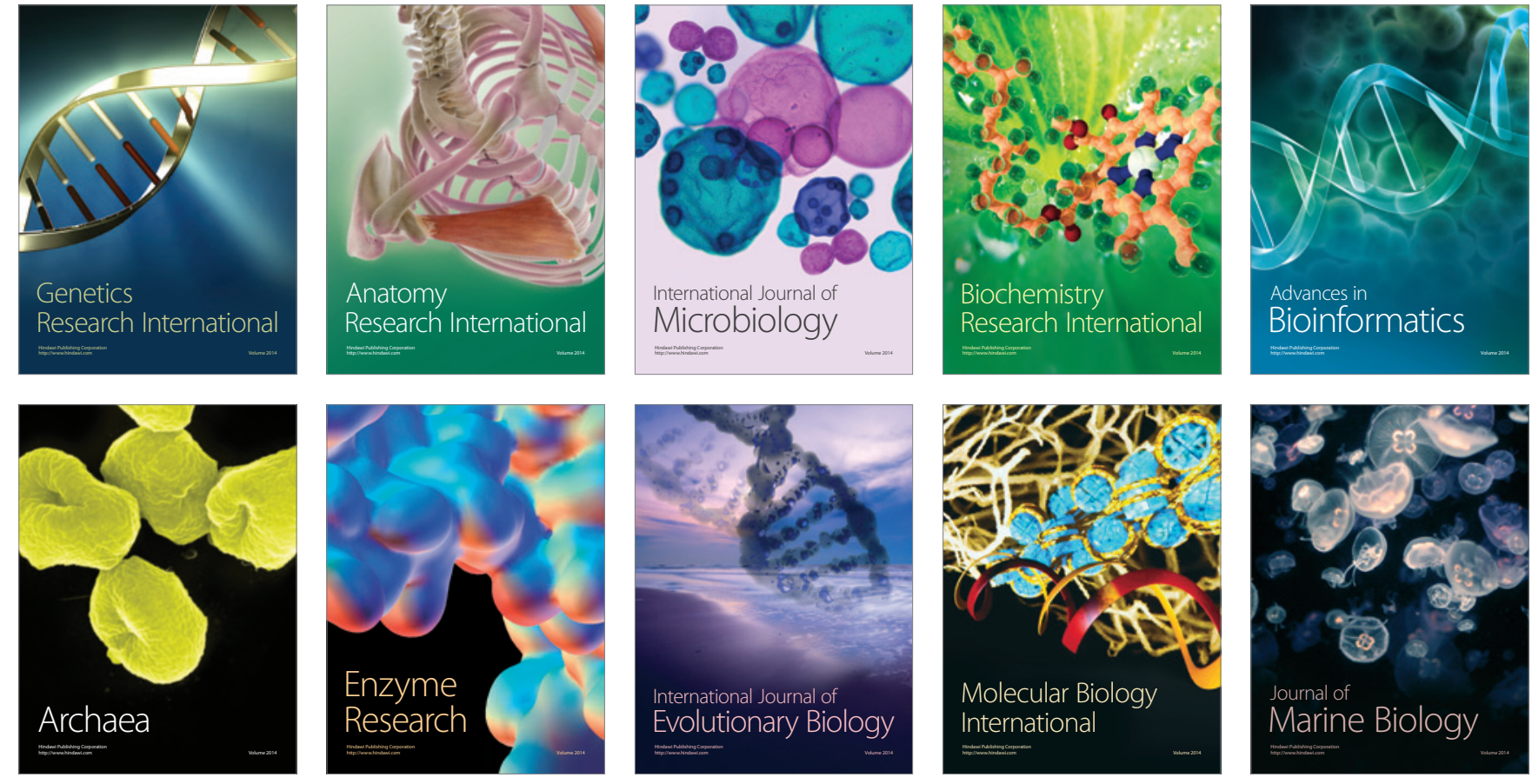